\title{
ENSINO BASEADO EM EQUIVALÊNCIA E PRODUÇÃO DE SENTENÇAS EM CRIANÇAS COM IMPLANTE COCLEAR
}

\section{EQUIVALENCE-BASED INSTRUCTION AND SENTENCE PRODUCTION IN CHILDREN WITH COCHLEAR IMPLANT}

\author{
ANDERSON JONAS DAS NEVES - ORCID 0000-0001-5138-0072 \\ UNIVERSIDADE FEDERAL DE São CARLOS, BRASIL \\ Instituto NaCional de CIÊNCIA e TeCnOlogia - Comportamento, Cognição e Ensino, BRAsil \\ Ana Claudia Moreira Almeida-Verdu - ORCID 0000-0001-5202-0263 \\ ${ }_{3}$ UNIVERSIDADE ESTADUAL PAULISTA, BRASIL

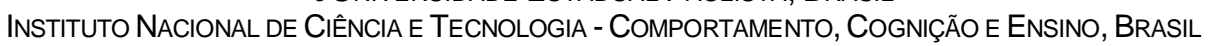

LEANDRA TABANEZ DO NASCIMENTO SILVA - ORCID 0000-0002-2472-4180

HOSPITAL dE REABILITAÇÃO de ANOMALIAS CRANIOFACIAIS, BRASIL

\author{
ADRIANE LIMA MORTARI MORET - ORCID 0000-0002-1776-9209 \\ UNIVERSIDADE DE SÃo PAULO, BRASIL

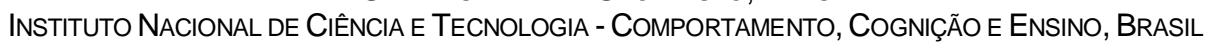

\section{RESUMO}

O ensino baseado em equivalência pode integrar repertórios verbais distintos e promover a precisão da fala em crianças com implante coclear, fato que tem sido observado com palavras e estendido recentemente para sentenças. O presente estudo replicou um estudo prévio e verificou os efeitos do ensino baseado em equivalência sobre a precisão da fala na nomeação de figuras de cenas e a produtividade oral de sentenças (nomear novas figuras relacionadas às sentenças recombinadas), em cinco crianças com implante coclear e leitoras. Os estímulos foram organizados em uma matriz que produziu nove sentenças de três termos, com estrutura sujeito-verbo-objeto (SVO) e o objeto comum; as três sentenças da diagonal da matriz foram ensinadas $\mathrm{e}$ as demais testadas. $\mathrm{O}$ ensino consistiu em selecionar figuras de cenas (por emparelhamento de acordo com o modelo, MTS) e construir sentenças impressas (por emparelhamento de acordo com o modelo com resposta construída, CRMTS), condicionalmente às sentenças ditadas. Pós-testes de leitura de sentenças impressas e de nomeação de figuras de cenas ocorreram para as sentenças ensinadas e recombinadas. Todos os participantes aprenderam as relações ensinadas, demonstraram relações de equivalência, aumentaram a precisão da fala diante das figuras de cenas e foram capazes de nomear figuras usando as sentenças recombinadas. Nossos resultados replicaram estudos prévios e aumentaram a generalidade dos achados com mais participantes. $\mathrm{O}$ aumento na precisão da linguagem oral em crianças com implante coclear e leitoras pode ser obtida por meio de ensino baseado em equivalência e ensino por matrizes.

Palavras chave: Ensino baseado em equivalência, matriz, produção oral, sentenças, implante coclear.

\section{ABSTRACT}

The equivalence-based instruction can integrate different verbal repertories and promote the speech accuracy in children with cochlear implant, a fact that has been observed with words and, recently extended to sentences. The present study replicated a previous study and verified the effects of equivalence-based instruction on speech accuracy in naming of pictures of scenes and oral productivity of sentences (to name novel pictures related to recombined sentences), in five children with cochlear implant and readers. The stimuli were organized in a matrix that produced nine sentences of three-terms, with subjectverb-object (SVO) structure and common object; the three sentences of matrix diagonal were taught, and others probed. The teaching consisted to select pictures of scenes (by matching-to-sample procedure, MTS) and construct printed sentences (by constructed-response-matching-to-sample, CRMTS), conditionally to dictated sentences. Reading of printed sentences and naming of pictures of scenes posttests occurred for taught and recombined sentences. All participants learned the taught relations, demonstrated equivalence relations, increased the speech accuracy in response to pictures of scenes, and were able to name pictures using recombined sentences. Our results replicated previous studies and increased generality findings with more participants. The increase of accuracy of oral language in children with cochlear implants and readers can be obtained through equivalence-based instruction and matrices training.

Keywords: equivalence-based instruction, matrix, oral production, sentences, cochlear implant.

\footnotetext{
Este artigo é parte da dissertação do primeiro autor, sob orientação da segunda autora e co-orientação da terceira e quarta autoras. O estudo foi subsidiado pela Fundação de Amparo a Pesquisa do Estado de São Paulo (FAPESP\#2012/05696-0) e apoio do Instituto Nacional de Ciência e Tecnologia - Comportamento, Cognição e Ensino (INC\&T - ECCE; CNPq\#573972/2008-7 e FAPESP\#2008/57705-8). Agradecemos às crianças e aos responsáveis pela participação e o Serviço de Implante Coclear do HRAC pelo apoio científico. Correspondência dever ser endereçada a Anderson Jonas das Neves (filosofoajn@gmail.com).

DOI: http://dx.doi.org/10.18542/rebac.v15i1.7918
} 
O desenvolvimento da linguagem, de palavras às sentenças, requer a aprendizagem dos repertórios iniciais de ouvinte e de falante (Greer \& Ross, 2008; Skinner, 1957). Prejuízos sensorioneurais no sistema auditivo, que afetam a detecção sonora inferior a 70 decibéis e que ocorrem antes da aquisição da linguagem oral, inviabilizam o acesso aos sons e ao feedback auditivo da produção oral, o que compromete a aprendizagem das habilidades auditivas e da linguagem falada (Fagan \& Pisoni, 2010; Levine, Stother-Garcia, Golinkhoff, \& Hirsh-Pasek, 2016; Moret, Bevilacqua, \& Costa, 2007).

Para populações com essas limitações sensórioauditivas, o implante coclear (IC) se configura em uma alternativa tecnológica para habilitar as funções auditivas e promover a linguagem oral (Svirsky, 2017; Svirsky, Robbins, Kirk, Pisoni, \& Miyamoto, 2000). Por meio de eletrodos inseridos na cóclea, o IC substitui o órgão de Corti (órgão sensorial da audição) e estimula eletricamente as fibras auditivas nervosas, o que proporciona uma sensação auditiva, sobretudo na frequência dos sons da fala, e um feedback acústico para a produção oral. Essas condições são importantes para aprender a ouvir e a falar (Peterson, Pisoni, \& Miyamoto, 2010; Spencer \& Oleson, 2008).

O IC assegura imediatamente a detecção dos sons, enquanto habilidades auditivas mais complexas (como discriminação, reconhecimento e compreensão auditivas; Erber, 1982) requerem a aprendizagem do uso do dispositivo (Fagan \& Pisoni, 2010). A aprendizagem de habilidades complexas, como a compreensão auditiva, pode ser estudada a partir do modelo das relações de equivalência, que fornece uma descrição operacional do funcionamento simbólico. Esse modelo prevê que relações de equivalência podem ser estabelecidas por meio do ensino direto de duas ou mais relações entre estímulos distintos (como sons, figuras e texto), ou entre estímulos e respostas, com pelo menos um elemento comum (Sidman, 2000; Sidman \& Tailby, 1982). Um ensino com essas características pode economizar tempo e produzir mais que as relações ensinadas, derivando relações que serão consideradas simbólicas se atestarem as propriedades formais da equivalência, que são a simetria (se A1rB1, logo B1rA1), a reflexibilidade (A1rA1 e B1rB1) e a transitividade (se A1rB1 e A1rC1, logo B1rC1); "r" descreve "está relacionado com" (Sidman \& Tailby, 1982).

O emparelhamento de acordo com o modelo (matching-to-sample, MTS) tem sido frequentemente adotado para ensinar relações condicionais entre estímulos. Esse procedimento define que um estímulo modelo estabelece condições para que um dos estímulos de comparação exerça função discriminativa e seja selecionado $(\mathrm{S}+)$, dentre os demais disponíveis para escolha (Mackay \& Sidman, 1984; Sidman \& Tailby, 1982). Um exemplo de ensino por MTS seria ditar /cone/ como modelo e apresentar três figuras como comparações (cone, dado e cubo), sendo o reforço contingente apenas à seleção da figura do cone; em outro ensino por MTS, /cone/ ditado estabeleceria condição para que a seleção da palavra escrita CONE fosse reforçada e não a seleção das palavras escritas DADO e CUBO. De acordo com o modelo das relações de equivalência, o ensino dessas relações condicionais arbitrárias, cuja a palavra ditada /cone/ é elemento comum, pode produzir relações condicionais nãoensinadas diretamente entre a figura do cone e a palavra escrita CONE; resultados positivos nas sondas dessas relações atestam a formação da classe de estímulos equivalentes entre /cone/ ditado, CONE escrito e figura do cone, e indicam a compreensão em leitura.

Estudos em interface entre a Fonoaudiologia e a Análise do Comportamento têm investigado sob quais condições se estabelecem as habilidades complexas do ouvir e sob quais condições a aprendizagem do ouvir pode estar relacionada com o surgimento do falar com precisão, em usuários de IC. As pesquisas iniciais estenderam o modelo das relações de equivalência (Sidman \& Tailby, 1982) para investigar o funcionamento simbólico com estímulos auditivos em usuários de IC, pré e pós-linguais, e verificaram a formação de classes de equivalência entre estímulos visuais e estímulos elétricos liberados diretamente em regiões da cóclea de participantes, e entre estímulos visuais e estímulos linguísticos (i. e., palavras com e sem história experimental anterior) que eram ditados (Almeida-Verdu et al., 2008; Battaglini, Almeida-Verdu, \& Bevilacqua, 2013; da Silva et al., 2006).

Os estudos de Almeida-Verdu et al. (2008) e Battaglini et al. (2013) sondaram a nomeação das figuras após a formação de classes de equivalência e identificaram que crianças com IC pré-linguais tinham uma fala que correspondia pouco às convenções linguísticas quando nomeavam figuras, mesmo após os estímulos auditivos e visuais tornarem-se equivalentes. Esses resultados são consistentes com achados da Fonoaudiologia de que usuários de IC pré-linguais aprendem habilidades auditivas e seus desempenhos ficam muito próximos aos dos pares ouvintes, enquanto as habilidades expressivas não acompanham o mesmo ritmo de aquisição das habilidades auditivas (Moret et al., 2007); além da menor variação de vocabulário (Lund \& Douglas, 2016), a produção da fala é marcada por omissões, trocas e distorções (Ruff et al., 2017).

Considerando que usuários de IC pré-linguais apresentam menor precisão nas habilidades expressivas que envolvem a fala (se comparada aos pares ouvintes), estudos subsequentes investigaram sob quais condições a precisão da fala seria obtida para essa população e com diferentes extensões linguísticas (Almeida-Verdu \& Gomes, 2016; Anastácio-Pessan, Almeida-Verdu, Bevilacqua, \& de Souza, 2015; Lucchesi, AlmeidaVerdu, Buffa, \& Bevilacqua, 2015; Lucchesi, AlmeidaVerdu, \& de Souza, 2018; Neves, Almeida-Verdu, Assis, Silva, \& Moret, 2018; Rique, Almeida-Verdu, Silva, Buffa, \& Moret, 2017; Silva, Neves, \& Almeida-Verdu, 2017). Esses estudos partiram de um achado de Golfeto (2010) de que crianças com IC e leitoras tinham uma fala mais precisa diante do texto do que diante da figura. $\mathrm{Na}$ leitura (ou operante textual), a produção oral está sob controle do estímulo escrito (Skinner, 1957) e as 
unidades textuais operam como pistas discriminativas de quais fonemas emitir (relação grafofonêmica) (de Rose, 2005; Share, 1999); ao passo que na nomeação (ou operante tato), a produção da fala é controlada por estímulos não-verbais (Skinner, 1957) que não oferecem dicas do que deve ser falado. Essa diferença observada demostra uma independência funcional entre operantes verbais (Lamarre \& Holland, 1985; Skinner, 1957) que, no caso de crianças com IC e leitoras, é demonstrada entre os operantes de tato e textual. Esse achado subsidiou as propostas subsequentes de ensino para integrar leitura e nomeação de figuras (Almeida-Verdu \& Gomes, 2016; Anastácio-Pessan et al., 2015; Lucchesi et al., 2015, 2018; Neves et al., 2018; Rique et al., 2017; Silva et al., 2017).

$\mathrm{O}$ ensino baseado em equivalência (equivalencebased instruction, EBI) permite integrar operantes $\mathrm{e}$ estabelecer ou refinar um repertório verbal a partir de outro estabelecido, por transferência de funções entre estímulos equivalentes (Fienup \& Critchfield, 2011; Mackay \& Sidman, 1984; Sidman, 1986). Crianças ouvintes têm aprendido a ler a partir do nomear figuras, após um ensino que torna equivalentes palavras ditadas, palavras impressas e figuras; no EBI com essas características, o controle discriminativo da figura é estendido para o texto (de Souza et al., 1997). Na rota inversa, crianças com IC têm refinado a fala na nomeação de figuras a partir da leitura, e as funções discriminativas do estímulo textual sobre a precisão da fala têm sido estendidas para as figuras, após relações de equivalência com palavras (Almeida-Verdu \& Gomes, 2016; Anastácio-Pessan et al., 2015; Lucchesi et al., 2015; Rique et al., 2017) e com sentenças (Neves et al., 2018; Silva et al., 2017). Nos estudos com palavras (e.g., Almeida-Verdu \& Gomes, 2016; Anastácio-Pessan et al., 2015), crianças com IC e leitoras passaram por um EBI que incluiu relações condicionais entre palavras ditadas e figuras $(\mathrm{AB})$, palavras ditadas e impressas (AC) e sílabas ditadas e impressas (ACsil), e melhoraram a nomeação de figuras após formarem classes de estímulos equivalentes. De modo análogo, crianças com IC que não eram leitoras aprenderam a ler, por meio de programa de leitura em EBI, e aumentaram a precisão em nomeação de figuras (Lucchesi et al., 2015, 2018).

As habilidades de ouvir e falar sentenças envolvem uma aprendizagem mais complexa e requerem desde categorizar palavras em classes até estabelecer relações de ordem entre elas (Mackay, 2013; Skinner, 1957). Para construir sentenças como "Dani pega copo" e "Mila seca bule", o aprendiz deve classificar as palavras em classes (como a dos nomes "Dani" e "Mila", a dos verbos "pega" e "seca", e a dos objetos "copo" e "bule") e arranjá-las na ordem convencionada [sujeito]-[verbo][objeto] (SVO). O ensino por matrizes (Frampton, Wymer, Hansen, \& Shillingsburg, 2016; Goldstein, 1983), o emparelhamento de acordo com modelo com resposta construída (Constructed-response matching-tosample, CRMTS) (Mackay, 2013) e, também, a combinação de ambos (Yamamoto \& Miya, 1999) são alguns procedimentos que podem ensinar relações de ordem entre palavras, que estão nas bases das relações sintáticas da linguagem. Um potencial desses procedimentos de ensino é o de promover a generalização recombinativa, de modo que ocorra um responder preciso às novas combinações de estímulos que recombinam componentes dos estímulos anteriormente ensinados (Goldstein, 1983). A generalização recombinativa embasa a produtividade de sentenças e pode ser observada quando o aprendiz é capaz de recombinar palavras que ocupavam a mesma posição sintática nas sentenças ensinadas; logo, após aprender a nomear as figuras de cenas "Dani pega copo" e "Mila seca bule", o aprendiz poderá nomear novas figuras usando sentenças recombinadas como "Dani seca bule", "Mila pega copo", "Dani pega bule", "Dani seca copo", "Mila seca copo" e "Mila pega bule" porque aprendeu a relação sintática envolvida (sujeito $\rightarrow$ verbo $\rightarrow$ objeto).

O ensino por matrizes consiste em distribuir estímulos em linhas e colunas da matriz, de modo que a intersecção dos componentes produza combinações linguísticas (Goldstein, 1983); algumas combinações são diretamente ensinadas e as demais testadas para verificar a generalização recombinativa. Golfeto e de Souza (2015) estenderam o potencial do ensino de sentenças para crianças com IC e programaram matrizes em que três sujeitos foram dispostos nas linhas, três verbos no gerúndio nas colunas e o objeto ficou constante, produzindo nove combinações [sujeito]-[verbo auxiliar + gerúndio]-[objeto]; foram ensinadas seis sentenças e as outras três testadas. Os participantes aprenderam diretamente a selecionar vídeos de ações condicionados às sentenças ditadas com três conjuntos de estímulos. A nomeação precisa dos vídeos ocorreu depois do treino de ecoico das sentenças ditadas, e os participantes foram capazes de nomear vídeos referentes às três sentenças não diretamente ensinadas.

$\mathrm{O}$ ensino por matrizes pode ser combinado com o procedimento de CRMTS (Dube, McDonald, McIlvane, \& Mackay, 1991) para ensinar sentenças e favorecer um responder sob controle de cada unidade menor da sentença (no caso, as palavras), condicionalmente ao modelo apresentado (Yamamoto \& Miya, 1999); por exemplo, uma tarefa de CRMTS seria apresentar a sentença ditada "Mila pega copo" como modelo e palavras escritas (como MILA, DANI, PEGA, SECA, COPO e BULE) para serem escolhidas, de modo que uma criança pode aprender a selecionar cada uma das palavras em uma ordem definida, sendo o reforço contingente à construção da sentença escrita relacionada arbitrariamente ao modelo. Yamamoto e Miya (1999) combinaram ensino por matrizes e CRMTS para ensinar crianças com autismo a construir três sentenças impressas condicionalmente às figuras; como resultado, todos aprenderam as relações ensinadas e construíram corretamente sentenças impressas diante de novas figuras que recombinavam componentes dos estímulos ensinados.

Neves et al. (2018) adotaram EBI, que incluía CRMTS e matrizes, e avaliaram os efeitos sobre a 
precisão da fala na nomeação de figuras de cenas e a produtividade de sentenças em três crianças com IC e leitoras. As sentenças tinham três termos e foram planejadas por matriz $3 \times 3$, em que três sujeitos foram dispostos nas linhas, três verbos nas colunas, o objeto permaneceu constante e a intersecção entre esses componentes gerou nove combinações [sujeito]-[verbo][objeto]; as sentenças da diagonal da matriz foram ensinadas, enquanto as demais apenas avaliadas. O EBI envolveu o ensino de relações condicionais entre sentenças ditadas e figuras de cenas (AB) por MTS e a construção de sentenças impressas condicionalmente às sentenças ditadas (AE) por CRMTS. Os participantes aprenderam as relações ensinadas ( $\mathrm{AB}$ e $\mathrm{AE}$ ), mas necessitaram de muitas repetições no ensino $\mathrm{AB}$ para atingir o critério de aprendizagem de $100 \%$ de acertos. Após o EBI, todos formaram relações de equivalência (entre sentenças ditadas, impressas e figuras de cenas), aumentaram a precisão da fala diante das figuras de cenas e foram capazes de nomear (BD) novas figuras por recombinação dos componentes das sentenças ensinadas. De modo análogo, em Silva et al. (2017), uma criança com IC que tinha habilidades de leitura rudimentar foi exposta ao mesmo EBI, com dois conjuntos de sentenças com cinco termos (artigo definido-sujeito-verbo-artigo indefinido-objeto), e foram obtidos resultados semelhantes nas relações semânticas e sintáticas.

Os resultados de Neves et al. (2018) e Silva et al. (2017) são promissores e sugerem o EBI e matrizes como uma rota eficiente para favorecer a nomeação precisa e a produtividade de sentenças dessa população. Replicar esses estudos com mais participantes permitiria avaliar a fidedignidade e generalidade desses achados (Byiers, Reichle, \& Symons, 2012; Munafò et al., 2017; Sidman, 1960). Nesse escopo, o presente estudo replicou o estudo de Neves et al. (2018) e avaliou os efeitos do EBI com matrizes sobre a nomeação precisa de figuras de cenas e a produtividade verbal, em crianças com IC e leitoras. Se sistematicamente replicados, os achados podem comprovar que condições de ensino baseadas no EBI e matrizes favorecem a precisão da fala e produtividade de sentenças para essa população, o que pode ajudar a tomar decisões baseadas em evidências científicas em contextos aplicados, como a reabilitação auditiva e a implementação de currículos.

\section{Participantes}

\section{MÉTODO}

Participaram do estudo cinco crianças, de oito a 11 anos, diagnosticadas com deficiência auditiva sensorioneural, pré-lingual, bilateral, usuárias de IC unilateral e de aparelho de amplificação sonora individual (AASI) contralateral. Os participantes frequentavam os anos iniciais do Ensino Fundamental I e eram periodicamente acompanhados pelo Serviço de Implante Coclear e pelo Centro Educacional do Deficiente Auditivo (CEDAU), ambos vinculados ao Hospital de Reabilitação de Anomalias Craniofaciais (HRAC), em Bauru. A pesquisa foi aprovada no Comitê de
Ética em Pesquisa (CAAE 01454412.0.0000.5441) e foram tomados todos os cuidados éticos.

O recrutamento ocorreu na Seção de Implante Coclear do HRAC e considerou a avaliação clínica da equipe. Os participantes foram avaliados em tarefas de leitura de sentenças impressas e de nomeação de figuras de cenas com as sentenças de ensino do estudo. Os critérios de inclusão foram desempenhos em leitura superiores a $70 \%$ de acertos e de nomeação de figuras inferiores a $50 \%$ na correspondência pontual com as convenções linguísticas.

Os participantes foram caracterizados a partir de informações declaradas em entrevistas com os responsáveis, em consulta aos prontuários e em avaliaçõesı que definem as categorias de audição e de linguagem (Moret et al., 2007). Resultados de vocabulário receptivo e de maturidade intelectual foram obtidos, respectivamente, pela aplicação individual do Peabody Picture Vocabulary Test (PPVT-4R) (Dunn \& Dunn, 2007) e do Teste Colúmbia (Alves \& Duarte, 1993). A Tabela 1 apresenta a caracterização dos participantes.

\section{Setting Experimental}

A sessão de avaliação ocorreu durante as visitas periódicas que os participantes realizavam na Seção de Implante Coclear do HRAC, em uma sala preparada com uma mesa, duas cadeiras, equipamentos de coleta e uma caixa de jogos e brindes. As demais sessões foram realizadas em uma sala do Centro de Psicologia Aplicada de uma universidade pública do interior paulista, com os mesmos mobiliários, equipamentos e materiais da sessão de avaliação.

\section{Equipamentos}

Foram utilizados um notebook com acesso ao software PROLER ${ }^{\circledR}$ versão 6.4 (Assis \& Santos, 2010), caixas de som, câmera filmadora, jogos e brindes. O software gerenciava a exposição às tarefas e registrava as respostas de seleção de estímulos e de construção. A tela do notebook exibia as tarefas e as consequências (quando ensino) e o touchpad do equipamento era acionado para selecionar os estímulos e construir a sentença impressa; era cedido um mouse para o participante realizar as tarefas, quando solicitado.

1As categorias de audição (Geers, 1994) variam de 0 a 6 e são definidas a partir da: avaliação clínica de comportamento auditivo; Teste de Avaliação da Capacidade Auditiva Mínima, Infant Toddler: Meaningful Auditory Integration Scale (Castiquini \& Bevilacqua, 2000), Procedimento para a Avaliação de Crianças Deficientes Auditivas Profundas, Lista de sentenças do dia-a-dia da língua portuguesa e Lista de palavras para percepção dos sons da fala. Já as categorias de linguagem estão distribuídas de 1 a 5 e são atribuídas com base na: avaliação da atitude de comunicação oral em situação de interação lúdica e em atividades direcionadas com a avaliadora e com o acompanhante da criança; Meaningful Use of Speech Scales (Robbins \& Osberger. 1991)

2 O PPVT-4R tem sido usado por diferentes profissionais (como fonoaudiólogos, educadores e psicólogos) para mensurar o vocabulário receptivo a partir dos dois anos e seis meses de idade, com valores padronizados para a população norte-americana. A forma A do PPVT-4R (Dunn \& Dunn, 2007) foi adaptada em uma versão em língua portuguesa, com uso restrito às condições de pesquisa, e tem sido combinada às medidas comportamentais de reconhecimento auditivo. 
Tabela 1

Caracterização dos participantes por gênero, idade, características da deficiência auditiva, tempo de audição com implante coclear (IC), tempo de audição com implante coclear (IC) em anos, modelo do implante coclear (IC), categoria de audição (CatAud), categoria de linguagem (CatLing), resultado do Columbia, escores do PPVT (Peabody Picture Vocabulary Test-4Ed) e ano escolar.

\begin{tabular}{|c|c|c|c|c|c|c|c|c|c|c|}
\hline Part & Gênero & $\begin{array}{l}\text { Idade } \\
\text { (anos) }\end{array}$ & $\begin{array}{l}\text { Deficiência } \\
\text { Auditiva }\end{array}$ & $\begin{array}{c}\text { Tempo audição } \\
\text { com IC } \\
\text { (em anos) }\end{array}$ & Modelo do IC & CatAud & CatLing & Columbia & PPVT & $\begin{array}{c}\text { Ano } \\
\text { Escolar }\end{array}$ \\
\hline SUE & $\mathrm{F}$ & 8 & $\begin{array}{l}\text { Sensorioneural } \\
\text { Profundo bilateral }\end{array}$ & 6 & Med-El Pulsar CI100106654 & 6 & 5 & Média & $05: 7$ & $2^{\circ}$ ano \\
\hline LUI & M & 8 & $\begin{array}{c}\text { Sensorioneural } \\
\text { Profundo bilateral }\end{array}$ & 7 & Nucleus 24K CI24RST & 6 & 5 & Média & $06: 3$ & $2^{\circ}$ ano \\
\hline LUC & M & 10 & $\begin{array}{l}\text { Sensorioneural } \\
\text { Severo Bilateral }\end{array}$ & 8 & Nucleus 24K CI24RST & 6 & 5 & Média & 09:6 & $4^{\circ}$ ano \\
\hline EDU & M & 11 & $\begin{array}{c}\text { Sensorioneural } \\
\text { Profundo bilateral }\end{array}$ & 7 & Med-El Pulsar CI100106654 & 6 & 4 & Média & $06: 3$ & $3^{\circ}$ ano \\
\hline LIN & M & 10 & $\begin{array}{c}\text { Sensorioneural } \\
\text { Profundo bilateral }\end{array}$ & 7 & Nucleus 24K CI24RST & 5 & 4 & $\begin{array}{l}\text { Média } \\
\text { Inferior }\end{array}$ & $04: 5$ & $3^{\circ}$ ano \\
\hline
\end{tabular}

As caixas de som reproduziam os estímulos auditivos que estavam programados nas tarefas auditivo-visuais e de produção oral. A produção oral foi gravada por uma câmera filmadora Sony® compacta, modelo JVC-GRAX837. Jogos foram usados nas atividades lúdicas e brindes (como livretos) foram escolhidos pelos participantes no fim das sessões.

\section{Tarefas experimentais}

As tarefas experimentais foram programadas no software PROLER ${ }^{\circledR}$, exibidas em tentativas discretas com a instrução, a apresentação dos estímulos, a oportunidade de responder, a consequência (se ensino) e o intervalo de $1 \mathrm{~s}$ entre tentativas. As tentativas no software exigiram respostas de seleção de estímulos, de construção e de produção oral.

Uma tentativa de seleção de estímulos consistiu na apresentação de um estímulo modelo no centro da tela e de estímulos de escolha dispostos nos cantos superior, inferior, direito e esquerdo do modelo (formato em cruz). A tarefa do participante era selecionar o estímulo de comparação correspondente ao modelo.

Nas tentativas de construção, o programa exibia o estímulo modelo na parte superior da tela, uma área intermediária (área de construção) e as palavras impressas dispostas na parte inferior da tela. A tarefa do participante era selecionar ordenadamente cada uma das palavras impressas, de modo a construir a sentença impressa relacionada ao modelo. Cada vez que uma palavra era selecionada, essa se deslocava para uma área intermediária (área de construção), na direção da esquerda para a direta. Em tarefas de seleção e construção em que o modelo era auditivo, a seleção do quadrado azul no centro da tela habilitava simultaneamente a reprodução do estímulo auditivo pelas caixas de som e a exibição dos estímulos de escolha na tela.

Nas tentativas de produção oral, o programa exibia um estímulo (sentença impressa ou figura de cena) no centro da tela com um prompt auditivo específico ("O que está acontecendo?”, se figura e, "O que está escrito?", se sentença impressa). A tarefa do participante era nomear figuras de cenas ou ler sentenças em voz alta.

\section{Estímulos}

Os estímulos linguísticos foram sentenças formadas por três palavras com estrutura sintática [sujeito]-[verbo]-[objeto] (SVO). As sentenças foram planejadas em uma matriz de três linhas e três colunas (3x3) apresentada na Figura 1. As três palavras designativas de nomes próprios ("Beto", "Dudu" e "Juca") foram alocadas nas linhas, três verbos ("descasca", "espreme" e "rala") nas colunas e a palavra com função de objeto ("limão") permaneceu constante. A intersecção dos elementos nas linhas e nas colunas, acrescidas do objeto invariável, formaram nove combinações [sujeito]-[verbo][objeto]; as três sentenças localizadas na diagonal da matriz foram diretamente ensinadas $\mathrm{e}$ as outras seis testadas (Neves et al., 2018).

Os estímulos do estudo foram os mesmos de Neves et al. (2018). O conjunto A foi composto por sentenças ditadas (como "Beto descasca limão", "Juca espreme limão" e "Dudu rala limão"), apresentadas em voz feminina. O conjunto B era constituído por figuras de cenas, coloridas, em arquivos de fotografia com $500 \times 500$ dpi e que apresentavam cenas correspondentes às sentenças previstas. $\mathrm{O}$ conjunto $\mathrm{C}$ incluiu as sentenças impressas, digitadas em fonte Arial, tamanho 65 e no espaço de $3 \times 3 \mathrm{~cm}$. 


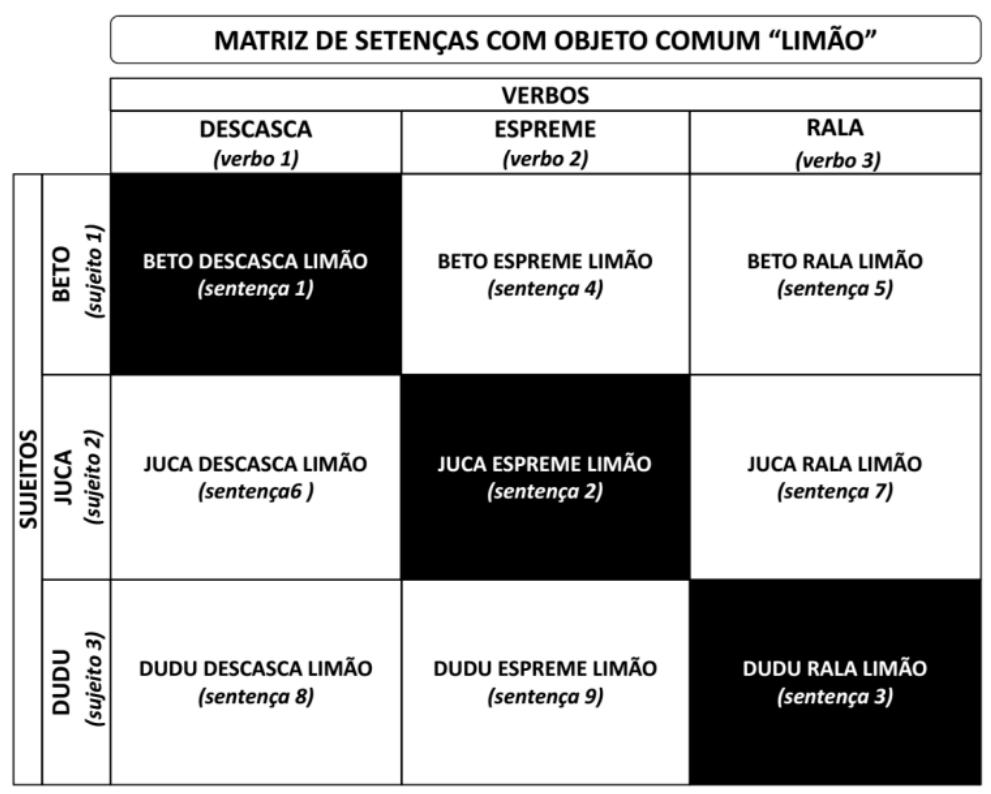

Figura 1. Matriz do estudo. As células como fundo preto (diagonal da matriz) indicam as sentenças que foram ensinadas e as células com fundo branco (seis células da matriz) indicam as sentenças que foram avaliadas. Adaptado de Neves et al. (2018).

\section{Delineamento}

$\mathrm{O}$ estudo adotou um delineamento de linha de base múltipla entre participantes (Kazdin, 1982). A exposição ao ensino foi feita de maneira controlada entre participantes e os desempenhos de leitura de sentenças e de nomeação de figuras de cenas foram sistematicamente monitorados.

\section{Procedimento}

As sessões foram individualizadas, ocorreram de uma a três vezes por semana e duraram, em média, 30 minutos cada. O participante era posicionado na frente do notebook, o pesquisador sentava-se do seu lado esquerdo e o instruía a operar as tarefas do software; quando o participante tinha dificuldades em seguir a instrução, foi dada uma dica física (e.g., segurar a mão para arrastar o cursor e clicar no estímulo com o mouse). Além disso, o pesquisador fornecia elogios contingentes ao sucesso nas tarefas de ensino e, ao final da sessão, eram realizadas atividades lúdicas (i.e., jogos, pintar, desenhar, brincar no tablet) por 10 minutos e o participante escolhia um brinde para levar consigo.

O presente estudo replicou o EBI de sentenças proposto por Neves et al. (2018) e adotou a mesma sequência de etapas, quais sejam, pré-teste, ensino, póstestes e avaliação da produtividade de sentenças, e dois follow-ups; esses follow-ups ocorreram uma semana e um mês após o participante realizar o último pós-teste. A etapa de revisão do ensino servia para remediar as dificuldades em nomear figuras e era aplicada somente se os resultados no primeiro pós-teste de nomeação das figuras de cenas fossem inferiores a $90 \%$ de acertos. Cada teste (pré, pós e follow-ups) e avaliação da produtividade de sentenças foi realizado em uma sessão e não havia critério e feedback; os follow-ups e a reaplicação da avaliação da produtividade de sentenças foram realizados na mesma sessão e aferiram a manutenção da aprendizagem.

$\mathrm{O}$ ensino foi programado por tentativa-e-erro. As tentativas exibiam apenas os estímulos alvo e as relações condicionais de ensino foram estabelecidas por meio de consequências diferenciais para respostas corretas (i.e., a seleção do S+ produzia a apresentação de gifs animados e elogios do pesquisador, como "Muito bem") e para respostas incorretas (i.e., a seleção do S- produzia a apresentação de uma tela preta por $3 \mathrm{~s}$ ), condicionalmente ao estímulo modelo.

\section{Testes}

Os testes ocorreram antes (pré-teste) e depois do ensino (pós-testes), e após se concluir a coleta (dois follow-ups, de uma semana e de um mês); quando o participante realizava a revisão do ensino, esses testes eram aplicados novamente logo após o bloco de revisão. Esses testes avaliaram relações envolvendo as três sentenças ensinadas (diagonal da matriz) e somaram 21 tentativas, que foram distribuídas em três blocos, a depender da resposta (produção oral, construção e seleção).

O bloco de teste da produção oral incluiu três tentativas de leitura de sentenças impressas (CD) e três de nomeação de figuras de cenas (BD); no pré-teste, esse bloco foi empregado para incluir o participante na pesquisa, a partir dos critérios mencionados ao descrever os participantes. O bloco de teste da resposta construída foi programado por meio de CRMTS e avaliou a construção de sentenças impressas condicionalmente à figura de cena $(\mathrm{BE})$ e à sentença ditada (AE); cada relação foi avaliada em uma tentativa, totalizando seis no bloco. O bloco de teste de seleção dos estímulos foi composto por nove tentativas, por 
MTS, e cada tentativa avaliou uma relação de seleção da figura de cena condicionalmente à sentença impressa (CB) e à sentença ditada (AB), e de seleção da sentença impressa condicionalmente à sentença ditada $(\mathrm{AC})$.

\section{Ensino}

O ensino de relações condicionais entre sentenças ditadas e figuras de cenas (AB) e da construção de sentenças condicionalmente à sentença ditada (ditado por construção, AE) foi organizado em blocos. O critério de aprendizagem foi $100 \%$ de acertos em cada bloco.

O bloco de ensino das relações condicionais entre sentenças ditadas e figuras de cenas (AB) apresentou randomicamente as nove tentativas de MTS, sendo três tentativas por sentença. Ao longo do bloco, os estímulos modelos foram alternados e os estímulos de comparação apresentados simultaneamente, sendo randomizadas as posições. $\mathrm{O}$ participante seguia para o bloco de construção de sentenças impressas sob ditado (AE) se atingisse o critério; caso erros ocorressem, o participante repetia até duas vezes o bloco e, depois, a sessão era encerrada e o ensino retomado na próxima sessão.

O ensino da construção de sentenças impressas condicionalmente às sentenças ditadas (AE) foi organizado em três blocos de tentativas de CRMTS. Cada bloco de ensino AE apresentava três tentativas e ensinava a construir uma sentença impressa sob ditado (AE): uma mesma sentença era ditada como modelo e somente as palavras que compunham a sentença impressa (S-V-O) estavam disponíveis para seleção $(\mathrm{S}+)$, não havendo estímulos a serem rejeitados (S-) ou distratores no rol de escolha. A posição das palavras a serem selecionadas $(\mathrm{S}+)$ foram randomizadas nas sucessivas tentativas. Se o critério não fosse atingido, eram realizadas até duas repetições e, se erros continuassem, a sessão era suspensa e a tarefa de ensino retomada na sessão seguinte. O primeiro bloco ensinou a construir uma sentença impressa a partir da sentença ditada "Beto descasca limão" (A1E1); em seguida, o bloco de ensino da relação de construção sob ditado da sentença "Juca espreme limão" (A2E2) e depois o bloco para construir a sentença impressa quando "Dudu rala limão" era ditado (A3E3).

Após o ensino das três relações de construção em separado, foi apresentado um bloco de nove tentativas com as três relações de construção juntas (A1E1, A2E2 e A3E3), com três tentativas por sentença. Ao longo das tentativas, os estímulos modelos foram alternados e foram apresentadas somente as palavras impressas a ser escolhidas $(\mathrm{S}+)$ e que estavam relacionadas ao modelo. O critério do bloco também foi $100 \%$ de acertos; se não fosse atingido, o participante era redirecionado para o ensino separado das três relações de construção.

\section{Revisão do Ensino}

A etapa de revisão do ensino tinha função remediativa e visava aumentar a precisão da fala na nomeação de figuras de cenas (BD) por meio de sucessivas oportunidades de rever as relações ensinadas (AB e $\mathrm{AE}$ ). A revisão consistiu em um bloco de nove tentativas de MTS (das relações sentença ditada-figura de cena A1B1, A2B2 e A3B3) seguido por um bloco de nove tentativas de CRMTS (construção de sentenças impressas sob ditado A1E1, A2E2 e A3E3), com consequências programadas para acerto e erro em cada tentativa de MTS e CRMTS.

O critério para realizar a revisão era uma nomeação de figuras de cenas menor que $90 \%$ de acertos no primeiro pós-teste. Após cada revisão de ensino, o participante era exposto novamente aos testes de nomeação de figuras de cenas (BD) e leitura de sentenças impressas (CD). A exposição aos blocos de revisão era encerrada se o participante obtivesse $100 \%$ de acertos no pós-teste de nomeação de figuras, ou se mantivesse a porcentagem de acertos na nomeação de figuras em dois pós-testes consecutivos.

\section{Avaliação da produtividade oral de sentenças}

$\mathrm{O}$ teste de produtividade oral de sentenças avaliou se o ensino das sentenças da diagonal da matriz promoveria a produção oral das seis sentenças referentes às demais células da matriz (vide Figura 1). As sentenças testadas e que recombinavam as palavras das sentenças ensinadas foram "Beto espreme limão", "Beto rala limão", "Juca descasca limão", "Juca rala limão", "Dudu descasca limão" e "Dudu espreme limão".

O bloco apresentava randomicamente seis tentativas de leitura das sentenças impressas (CD) e seis tentativas de nomeação de figuras de cenas (BD), de modo que a produção oral das sentenças recombinadas foi avaliada sob duas situações, sendo uma de leitura e outra de nomeação de figuras. Os participantes realizavam esse teste imediatamente após a conclusão de cada pós-teste, na mesma sessão.

\section{Análise de dados e concordância entre observadores}

Os acertos nas tentativas de seleção de estímulos e de construção foram registrados em relatórios individualizados do software PROLER $®$. O desempenho nessas tarefas foi analisado individualmente, em porcentagem de acertos, por relação e por bloco.

A produção oral dos participantes foi registrada em vídeo e transcrita por dois observadores independentes. Após transcritas, a precisão da fala foi analisada de acordo com a correspondência entre os fonemas produzidos pelo participante e os fonemas-alvo da sentença (Camarata, 1993), a partir das convenções do Português Brasileiro Falado. O desempenho na produção oral foi convertido em porcentagem e computado pela razão entre fonemas produzidos corretamente pelo total de fonemas, multiplicada por 100. Dado o exemplo, a vocalização /Dudu raga nimão/ tem 11 fonemas corretos em relação ao alvo/Dudu rala limão/ (13 fonemas), resultando em 11/13 ou 84,61\% de precisão. 
A concordância entre observadores foi aplicada apenas às tarefas de produção oral. Os observadores assistiram os vídeos e transcreveram, de modo independente, a fala dos participantes nas tarefas de leitura de sentenças e na nomeação de figuras de cenas. A concordância foi calculada para cada sentença e adotou a seguinte fórmula: número de concordâncias / número de concordâncias + número de discordâncias $\mathrm{x}$ 100 (Kazdin, 1982). A concordância, para cada sentença, foi igual ou superior a $93,89 \%$ e sugere uma validade interna dos dados de produção oral.

\section{RESULTADOS}

Todos os participantes concluíram o estudo e foram necessárias, em média, 15 sessões; os follow-ups não foram computados. Os participantes obtiveram o critério de aprendizagem nos blocos de ensino $\mathrm{AB}$ e $\mathrm{AE}$ (100\% de acertos) e demonstraram formação das relações de equivalência (entre sentenças ditadas e impressas e figuras de cenas) em momentos diferentes. A Tabela 2 exibe o número de exposições necessários para alcançar $100 \%$ de acertos nos blocos de ensino e nos sucessivos testes de equivalência (relações $\mathrm{CB}$ e BE).

Tabela 2

Número de exposição aos blocos de ensino e testes, até adquirir o critério. Adaptada de Neves et al. (2018).

\begin{tabular}{|c|c|c|c|c|c|c|c|}
\hline \multirow[t]{3}{*}{ Participante } & \multicolumn{5}{|c|}{ Ensino } & \multicolumn{2}{|c|}{ Testes de equivalência } \\
\hline & \multirow{2}{*}{$\begin{array}{c}\text { Seleção de figuras de } \\
\text { cenas condicionadas às } \\
\text { sentenças ditadas (AB) } \\
\text { (A1B1, } \\
\text { A2B2, A3B3) }\end{array}$} & \multicolumn{4}{|c|}{$\begin{array}{l}\text { Construção de sentenças } \\
\text { impressas condicionadas às } \\
\text { sentenças ditadas (AE) }\end{array}$} & \multirow{2}{*}{$\begin{array}{c}\text { Construção de sentenças } \\
\text { impressas condicionadas às } \\
\text { figuras de cenas (BE) } \\
\text { (B1E1, } \\
\text { B2E2, } \\
\text { B3E3) }\end{array}$} & \multirow{2}{*}{$\begin{array}{c}\text { Seleção de figuras de } \\
\text { cenas condicionadas às } \\
\text { sentenças impressas (CB) } \\
(\mathrm{C} 1 \mathrm{~B} 1, \\
\text { C2B2, } \\
\text { C3B3) }\end{array}$} \\
\hline & & A1E1 & $\mathrm{A} 2 \mathrm{E} 2$ & A3E3 & $\underset{\text { (simultâneo) }}{\mathrm{AE}}$ & & \\
\hline SUE & 5 & 1 & 1 & 1 & 2 & 2 & 2 \\
\hline LUI & 8 & 3 & 1 & 2 & 4 & 1 & 1 \\
\hline LUC & 3 & 2 & 1 & 2 & 1 & 1 & 1 \\
\hline LIN & 6 & 1 & 1 & 1 & 1 & 1 & 2 \\
\hline EDU & 11 & 1 & 1 & 1 & 1 & 2 & 2 \\
\hline Média & 6,6 & 1,6 & 1 & 1,4 & 1,8 & 1,4 & 1,6 \\
\hline
\end{tabular}

Os participantes tiveram repetições no bloco de ensino das relações condicionais entre sentenças ditadas e figuras de cenas $(\mathrm{AB})$, com média de 6,6 exposições. EDU e LUI foram os que mais repetiram o ensino $A B$, respectivamente, 11 e oito exposições. Os demais participantes (SUE, LUC e LIN) demandaram de três a seis exposições para aprender $\mathrm{AB}$.

Durante o ensino da construção de sentenças impressas sob ditado (AE), praticamente todos os participantes alcançaram $100 \%$ de acertos na primeira exposição aos blocos A1E1, A2E2 e A3E3; quando necessário, poucas repetições foram feitas, com média de 1,6 exposições ao bloco A1E1, de 1,0 ao bloco A2E2 e de 1,4 ao bloco A3E3. Quando o bloco apresentou as três relações de construção juntas (AE simultâneo), LUC, EDU e LIN atingiram o critério logo na primeira exposição, enquanto SUE precisou de duas exposições e LUI precisou de quatro exposições para obter $100 \%$ de acertos.

Todos os participantes alcançaram 100\% de acertos nos testes das relações derivadas (CB e BE), que foi obtida em momentos diferentes para cada participante (vide Tabela 2); imediatamente após o ensino para LUI e LUC, e após uma revisão do ensino para os demais participantes (SUE, LIN e EDU). A Tabela 3 apresenta o desempenho dos participantes nos pré e pós-testes envolvendo seleção de estímulos e construção.

Os participantes apresentaram variações das porcentagens de acertos nos pré-testes de construção de sentenças impressas, independente do controle condicional (sentenças ditadas ou figuras de cenas); LUC obteve $100 \%$ de acertos, SUE e LUI tiveram menos que $66 \%$ de acertos, e LIN e EDU variaram as porcentagens de acertos nas tarefas envolvendo as sentenças ditadas $(0 \%$ a $100 \%$ para LIN e $66,7 \%$ a $100 \%$ para EDU) e as figuras de cenas $(66,7 \%$ a $100 \%$ para LIN e $100 \%$ para EDU). Os participantes mostraram diferenças nas porcentagens de acertos nas tarefas de seleção, a depender da relação entre estímulos que foi avaliada; na seleção de figuras condicionada às sentenças ditadas $(\mathrm{AB})$, as porcentagens de acertos foram entre $33,33 \%$ à $66,67 \%$, e na seleção de figuras de cenas condicionadas às sentenças impressas (CB) entre $0 \%$ à $66,67 \%$. Todos tiveram $100 \%$ de acertos na seleção de sentenças impressas condicionalmente ao modelo ditado (AC), no primeiro ou ao longo dos sucessivos pré-testes, exceto LIN que obtive entre $0 \%$ e $66 \%$ de acertos. Após o EBI, todos os participantes obtiveram $100 \%$ de acertos nas relações que envolveram resposta construída ( $\mathrm{AE}$ e $\mathrm{BE})$ e seleção de estímulos $(\mathrm{AB}$, $\mathrm{AC}$ e $\mathrm{CB})$.

As mudanças na precisão da fala de sentenças, em função do EBI, foram observadas nos desempenhos de leitura de sentenças impressas (CD) e de nomeação de figuras de cenas (BD). A Figura 2 apresenta esses resultados em linha de base múltipla entre participantes, para as sentenças ensinadas e recombinadas.

No pré-teste, os participantes tiveram acima de $70 \%$ de acertos na leitura de sentenças (CD) e menos de $50 \%$ de acertos na nomeação de figuras de cenas (BD), o 
que caracteriza a discrepância entre ler sentenças impressas e nomear figuras de cenas, que era critério de inclusão do estudo. Os desempenhos de leitura entre participantes variaram pouco nos pré-testes (variação de $73,91 \%$ a $100 \%$ de acertos), enquanto os de nomeação de figuras de cenas apresentaram maior variabilidade (entre $10,87 \%$ a $47,83 \%$ de acertos). Essa discrepância foi mantida nos sucessivos pré-testes, para todos os participantes.

Foi observado que os participantes LUI, LUC e EDU aumentaram a precisão da fala diante das figuras de cenas (BD) imediatamente após o EBI e alcançaram acima de $80 \%$ de acertos, com desempenhos próximos aos obtidos nos pós-testes de leitura de sentenças (CD) (92\% de acertos, em média); LUC obteve $100 \%$ de acertos no primeiro pós-teste de nomeação de figuras de cenas, enquanto LUI e EDU aumentaram a precisão ao longo das sucessivas sondas, com $95 \%$ de acertos (em média) no último pós-teste. Os demais participantes (SUE e LIN) aumentaram a precisão da fala diante das figuras de cenas (BD) para $97 \%$ de precisão (em média) depois de duas revisões do ensino, o que se aproximou mais da precisão nos pós-testes de leitura (CD).

Tabela 3

Porcentagem de acertos dos participantes nas relações que envolveram seleção de estímulos $(C B, A C$ e $A B) e$ construção (AE e BE) nos pré e pós-testes. Adaptada de Neves et al. (2018).

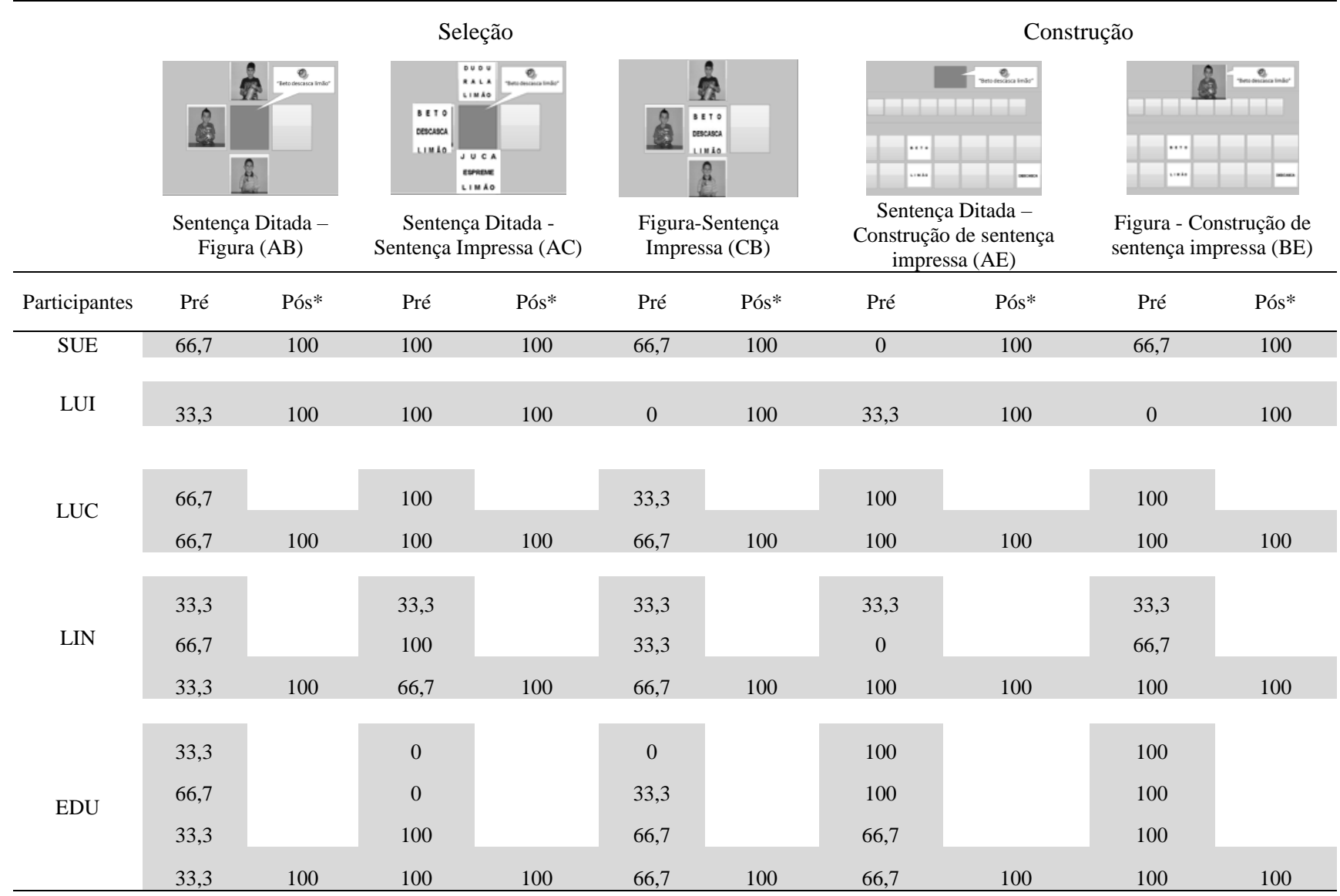

*Os dados do pós-teste referem-se à última exposição.

Todos os participantes mantiveram a nomeação de figuras de cenas (BD) superior a $90 \%$ de acertos no follow-up de uma semana. No follow-up de um mês, LUC e SUE mostraram os mesmos desempenhos em leitura de sentenças (CD) e em nomeação de figuras de cenas (BD), ao passo que LUI e EDU tiveram ligeira redução na nomeação de figuras de cenas, porém nunca retornaram aos níveis de linha de base (que era de 31,52\%, em média). LIN não realizou o follow-up devido a mudança de Estado.

Os participantes foram capazes de ler novas sentenças e de nomear novas figuras, recombinando os componentes das sentenças ensinadas em novas sentenças que referiam às seis células da matriz.

Nos pós-testes e nos follow-up, todos obtiveram acima de $78 \%$ de precisão na fala frente às sentenças impressas e às figuras de cenas novas, que recombinavam os componentes ensinados. LIN fez somente a avaliação após o EBI, pelos motivos já citados.

\section{DISCUSSÃO}

O presente estudo replicou o estudo conduzido por Neves et al. (2018) e os resultados indicam que os participantes com IC e leitores aumentaram a precisão da 
fala diante de figuras de cenas (BD) e foram capazes de produzir sentenças inéditas por recombinação dos componentes das sentenças ensinadas. Esses resultados sugerem a generalidade dos achados prévios, uma vez que o EBI e ensino por matrizes foram suficientes para promover o aumento na precisão da fala e a produtividade oral de sentenças na nomeação de figuras de cenas (BD) em todos os participantes do estudo.

Durante os pré-testes, os participantes tiveram uma fala mais precisa diante da sentença impressa do que diante da figura de cena. Essa discrepância, que era critério de inclusão, pode ser explicada em função de algumas variáveis. As características das figuras (como ser uma cena estática) podem ter estabelecido respostas de nomeação sob controle de um dos componentes da cena (como o objeto), de modo que o participante nomeava "faca limão" ao invés de "Beto descasca limão"; essas características podem ter constituído um artefato de procedimento que dificultou a ocorrência do comportamento de nomear corretamente (Neves et al., 2018). Essas topografias de controle de estímulos devem ser controladas em pesquisas futuras por meio da produção de figuras de cenas que evidenciem a ação, os objetos e o contexto.

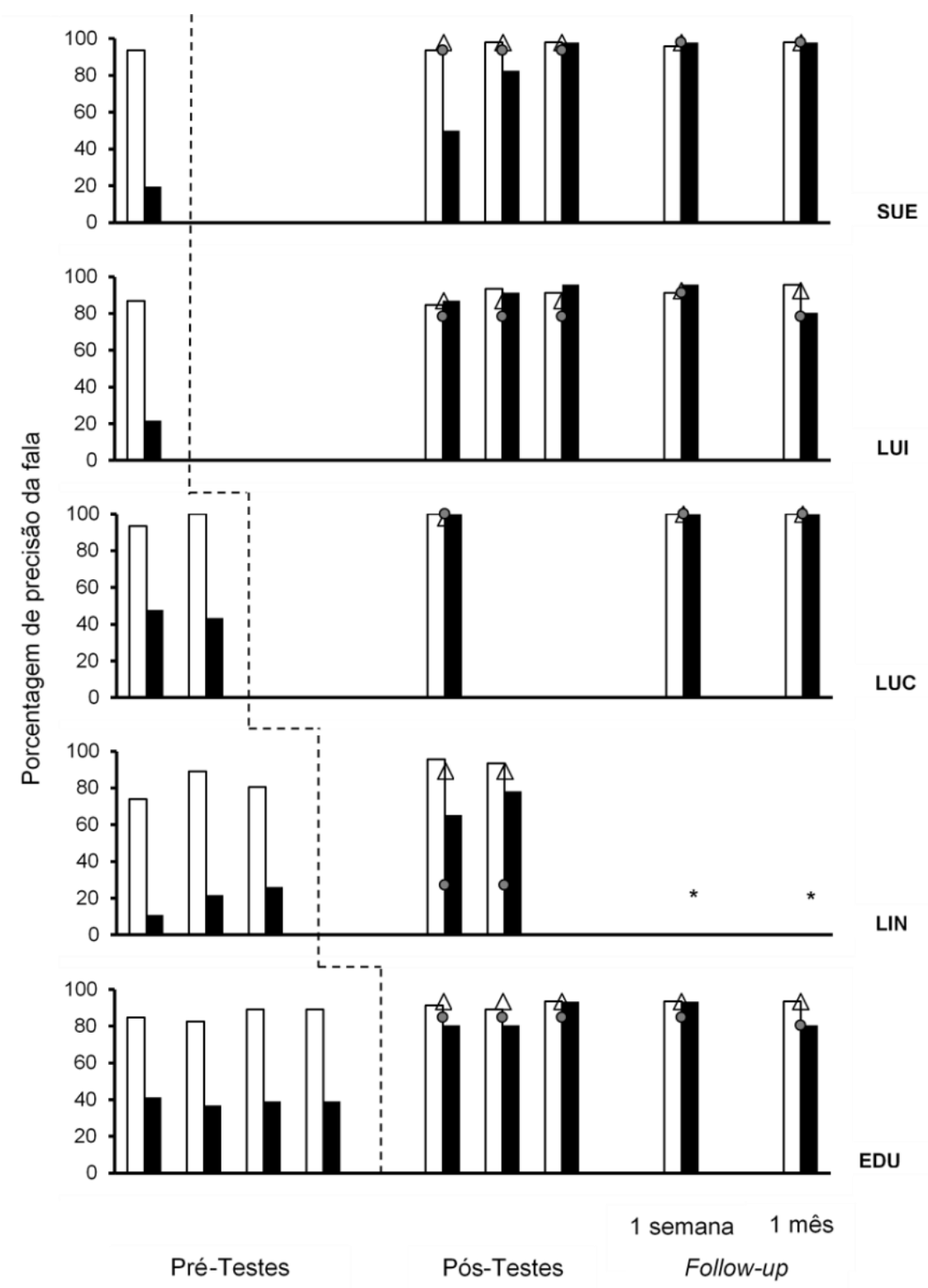

Figura 2. Desempenho em leitura de sentenças e nomeação de figuras de cenas, em linha de base múltipla entre participantes. A linha tracejada indica o ensino. As barras brancas indicam a leitura das sentenças de ensino, e as pretas a nomeação de figuras de cenas referentes às sentenças de ensino. $\mathrm{O}$ triângulo vazado refere à leitura de sentenças recombinadas, e o círculo cinza à nomeação usando as sentenças recombinadas. $\mathrm{O}$ asterisco $(*)$ indica ausência da sonda.

Nos pré-testes, a produção oral diante das figuras de cenas tinha pouca correspondência ponto-a-ponto com as convenções da comunidade verbal, embora alguns componentes das figuras tenham sido pronunciados corretamente (tais como o objeto "limão"). Ao nomear figuras de cenas usando a sentença "Beto descasca limão", 
por exemplo, os participantes emitiram /roanoarana/ (SUE e LUI), /tatado faca imao/ (LIN), /uaistemeimão/ (EDU) e /corta limão/ (LUC). Esses resultados confirmam achados da Fonoaudiologia de que a linguagem expressiva de crianças com IC pré-linguais é marcada por omissões, distorções e trocas na produção da fala (Lund \& Douglas, 2016; Ruff et al., 2017; Svirsky et al., 2000; Spencer \& Oleson, 2008); ainda, somam aos estudos prévios que observaram as dificuldades na precisão ao nomear oralmente as figuras, usando diferentes unidades linguísticas (Anástacio-Pessan et al., 2015; Lucchesi et al., 2015; Lucchesi et al., 2018; Neves et al., 2018; Rique et al., 2017; Silva et al., 2017).

A discrepância dos desempenhos de leitura de sentenças e de nomeação de figuras de cenas nos pré-testes reporta às relações de controle de estímulos. A produção oral que ocorre diante de um determinado estímulo (como a sentença impressa) pode simplesmente não ocorrer diante de outros estímulos (como a figura de cena), pois essa resposta depende da relação específica que foi estabelecida com o estímulo que a antecedeu (Skinner, 1957). A independência funcional entre operantes verbais de tato e textual (de mesma topografia) no presente estudo confirma achados de pesquisas com crianças com IC e leitoras (Anástacio-Pessan et al., 2015; Golfeto, 2010; Lucchesi et al., 2015; Neves et al., 2018; Rique et al., 2017; Silva et al., 2017) e também com outras populações entre operantes de tato e mando (Lamarre \& Holland, 1985) e operantes de topografias diferentes como ouvir e falar (Guess, 1969; Bandini et al., 2012). Considerando que a discrepância entre leitura e nomeação de figuras tem sido recorrentemente reportada em crianças com IC e leitoras, programas terapêuticos e educacionais podem planejar condições que visem integrar esses operantes verbais e os EBI's poderiam constituir em uma proposta (Fienup \& Critchfield, 2011).

O presente estudo confirma o EBI como uma rota eficiente para integrar operantes verbais de ler sentenças impressas e nomear figuras de cenas em crianças com IC e leitoras, replicando Neves et al. (2018) e Silva et al. (2017). Os participantes aumentaram a precisão da fala diante das figuras de cenas (BD) após o EBI e os desempenhos ficaram próximos aos observados na leitura de sentenças impressas (CD). Esse resultado pode ser explicado pela transferência de função entre estímulos equivalentes (Mackay \& Sidman, 1984), de modo que o controle que a sentença impressa exercia sobre a precisão da fala (na leitura) foi estendido para a figura de cena (na nomeação de figuras de cenas), por relações de equivalência; com efeito, houve redução da discrepância entre esses operantes. Os resultados evidenciam o potencial do EBI em produzir inter-relações entre esses operantes e em refinar a topografia vocal de um operante a partir de outro (de Rose, de Souza, \& Hanna, 1996; Sidman, 1986). Enquanto o EBI tem promovido leitura a partir da nomeação de figuras para crianças ouvintes (de Souza et al., 1997), crianças com IC mostraram que o EBI opera de modo inverso e estabelece uma nomeação precisa de figuras a partir da leitura, com palavras (AnástacioPessan et al., 2015; Lucchesi et al., 2015; Rique et al.,
2017) e, de modo recente, estendendo para sentenças (Neves et al., 2018; Silva et al., 2017).

Os participantes repetiram o ensino das relações condicionais entre sentenças ditadas e figuras de cenas (AB) e foram necessários, em média, 6,6 exposições para atingir $100 \%$ de acertos. Esse resultado também foi encontrado em estudos anteriores com sentenças (Neves et al., 2018; Silva et al., 2017). Uma hipótese é que o reconhecimento auditivo de sentenças configura uma tarefa difícil (Erber, 1982) e que exige responder às diversas dimensões do estímulo auditivo (como duração, segmentação e comprimento da sentença), o que talvez justifique os participantes demandarem mais tempo nesse ensino.

A repetição do ensino das relações condicionais auditivo-visuais diverge da literatura (Almeida-Verdu et al., 2008; Anastácio-Pessan et al., 2015; Battaglini et al., 2013) e pode estar relacionada a aspectos procedimentais. A maioria dos estudos em controle de estímulos e IC adotaram procedimentos de ensino que favorecessem uma aprendizagem rápida e com poucos erros, como ensino por exclusão e por fading out do componente visual de um modelo multicomponente (auditivo e visual) (AlmeidaVerdu et al., 2008; Anastácio-Pessan et al, 2015; Battaglini et al., 2013), enquanto o presente estudo empregou o procedimento de tentativa e erro, o que demandar mais repetições e suscetibilidade a erros (Ferrari, de Rose, \& McIlvane, 1993). Estudos futuros devem empregar procedimentos de ensino sem erros e avaliar os efeitos sobre a aprendizagem das relações arbitrárias envolvendo sentenças.

O ensino de construção de sentenças impressas sob ditado (AE) empregou o CRMTS e apresentou sentenças ditadas como modelo e somente as palavras impressas corretas $(\mathrm{S}+)$ no rol de escolha. Todos os participantes aprenderam a selecionar ordenadamente as palavras para construir a sentença impressa relacionada ao modelo (AE) e alcançaram 100\% de acertos em praticamente uma exposição ao ensino. Os resultados replicaram achados de estudos prévios (Neves et al., 2018; Silva et al., 2017) e confirmam que o ensino por CRMTS fortaleceu o controle pelas unidades mínimas, usualmente demonstrado pela literatura com palavras (Dube et al., 1991; Hanna, de Souza, de Rose, \& Fonseca, 2004; Matos, Avanzi, \& McIlvane, 2006). Adicionalmente, o CRMTS estabeleceu relações condicionais entre as sentenças ditadas e as sentenças impressas que foram produzidas pela resposta construída (Mackay \& Sidman, 1984; Sidman, 1986). O ensino de sentenças por CRMTS combinado com matrizes intensificou o controle por cada unidade mínima e pelas relações de ordem entre palavras nas sentenças, o que provavelmente promoveu condições para se formar classes sintáticas (dos primeiros, segundos e terceiros elementos) (Mackay, 2013; Yamamoto, \& Miya, 1999).

Outra questão importante é que o ensino AE pode ter estabelecido um controle múltiplo sob a resposta construída, quer seja pelo estímulo condicional (sentenças ditadas), quer seja pela apresentação restrita dos estímulos positivos $(\mathrm{S}+)$ no rol de construção, o que pode ter 
funcionado como dica para arranjar as palavras na ordem definida [sujeito]-[verbo]-[objeto], já que os participantes eram leitores. Esse controle conjunto - pelo modelo e pelas relações de ordem entre palavras - pode ser importante para crianças com IC aprenderem o reconhecimento auditivo e a produção oral de sentenças, mas essa hipótese precisa ser testada experimentalmente, por exemplo, inserindo estímulos a serem rejeitados (S-) ou distratores no rol de palavras para construção.

Os participantes do presente estudo foram capazes de, sem ensino direto, ler seis novas sentenças impressas e nomear seis novas figuras de cenas, por recombinação dos componentes ensinados. O ensino por matrizes tem sido efetivo para promover desempenhos recombinativos para diferentes populações (Frampton et al., 2016; Yamamoto \& Miya, 1999) e o presente estudo soma-se aos achados desses estudos e de outros com sentenças e crianças com IC (Golfeto \& de Souza, 2015; Neves et al., 2018; Silva et al., 2017); a generalização recombinativa de sentenças ocorreu nos diferentes estudos com crianças com IC, independente da sobreposição e do arranjo da matriz.

O presente estudo integra a gama de pesquisas que adotaram procedimentos operantes e matrizes (Goldstein, 1983) para produzir habilidades verbais com sentenças, para crianças com IC. Golfeto e de Souza (2015) foram pioneiras e verificaram que o ensino de relações condicionais auditivo-visuais (sentenças ditadascenas de vídeo) e treino ecoico, envolvendo seis sentenças, promoveu a nomeação das cenas ensinadas e de outras três inéditas referentes à diagonal da matriz que não foram diretamente ensinadas. Por outra rota, Neves et al. (2018) e Silva et al. (2017) mostraram os efeitos do EBI com as sentenças da diagonal da matriz, sobre a nomeação precisa de figuras de cenas ensinadas e a produtividade das seis sentenças referentes as demais células; o presente estudo replicou esses achados e aumentou a generalidade com mais participantes, fortalecendo cumulativamente as evidências (Sidman, 1960) de que o EBI de sentenças favorece a nomeação precisa de figuras de cenas e a produtividade de sentenças, para crianças com IC.

Os estudos em controle de estímulos, IC e sentenças (Golfeto \& de Souza, 2015; Neves et al., 2018; Silva et al., 2017) sugerem que diferentes procedimentos e rotas de ensino podem favorecer a nomeação precisa de figuras, quer os participantes apresentem repertório de leitura estabelecido ou habilidades verbais mais rudimentares. Esses achados lançam perspectivas futuras para se investigar procedimentos de ensino que produzam a aprendizagem e produtividade, semântica e sintática, de sentenças (Mackay, 2013; Neves et al., 2018; Yamamoto \& Miya, 1999), com potencial de aplicação em currículos e nas estratégias de reabilitação auditiva.

Os efeitos do EBI (variável independente, VI) sobre a nomeação precisa de figuras de cenas (variável dependente, VD) foram demostrados por meio da linha de base múltipla entre participantes. Algumas limitações no delineamento foram identificadas. O presente estudo registrou, para alguns casos, menos de três medidas da VD na linha de base, divergindo das recomendações de Gast e
Ledford (2014). Ainda, as tentativas com as sentenças recombinadas, que foram avaliadas apenas nos pós-testes do presente estudo, poderão ser incorporadas nas sondas gerais em estudos subsequentes, para garantir um maior controle experimental.

A instabilidade na VD durante a linha de base, com variabilidade e tendência sutil de melhora, comprometeu o controle experimental do estudo. Diferente da estabilidade de linha de base de algumas populações com repertório verbal mínimo (Frampton et al., 2016), crianças com IC podem mostrar um aumento da nomeação em função das interações verbais, da alfabetização e da reabilitação auditiva a que são expostas (Anastácio-Pessan et al., 2015; Lucchesi et al., 2015; Neves et al., 2018; Silva et al., 2017). Entretanto, essa melhora foi menor que $10 \%$ e todos mantiveram menos que $50 \%$ de acertos na nomeação de figuras de cenas nos pré-testes; e houve um aumento superior a $80 \%$ de acertos somente depois do $\mathrm{EBI}$, o que confere validade interna ao estudo. O presente estudo, aliado aos resultados de estudos anteriores, incorpora critérios de evidência científica em delineamentos de sujeito único. É pela repetição direta ou sistemática que se afirma a viabilidade de um procedimento ou técnica ser adotado em maior escala (Byiers et al., 2012; Munafò et al., 2017).

\section{DECLARAÇÃO DE CONFLITO DE INTERESSES}

Os autores declaram que não há conflito de interesses relativos à publicação do presente artigo.

\section{CONTRIBUIÇÃO DE CADA AUTOR}

AJN contribuiu na concepção do estudo, formulou o delineamento metodológico, realizou coleta e análise de dados, e redigiu o manuscrito. ACMAV contribuiu na concepção e coordenação do estudo, formulou o delineamento metodológico, colaborou na análise de dados, redigiu e revisou o manuscrito. LTNS e ALMM contribuíram na revisão da literatura pertinente à interdisciplinaridade, realizaram a avaliação e a análise dos dados clínicos dos participantes e revisaram o manuscrito.

\section{DIREITOS AUTORAIS}

Este é um artigo aberto e pode ser reproduzido livremente, distribuído, transmitido ou modificado, por qualquer pessoa desde que usado sem fins comerciais. $\mathrm{O}$ trabalho é disponibilizado sob a licença Creative Commons 4.0 BY-NC.

\section{(cc) EY-NC}

\section{REFERÊNCIAS}

Almeida-Verdu, A. C. M., \& Gomes, F. (2016). Precisão da fala em nomeação de figuras após formação de classes de equivalência em crianças com implante coclear. Perspectivas em Análise do Comportamento, 7(2), 274-287. doi: 10.18761/pac.2016.010

Almeida-Verdu, A. C. M., Huziwara, E. M., de Souza, D. G., de Rose, J. C., Bevilacqua, M. C., Lopes Jr., J, \& 
McIlvane, W. J. (2008). Relational Learning children with Deafness and Cochlear Implants. Journal of the Experimental Analysis of Behavior, 89(3), 407-424. doi: 10.1901/jeab.2008-89-407

Alves, I. C. B., \& Duarte, J. L. M. (1993). Padronização Brasileira da Escala de Maturidade Mental Colúmbia. In Burgemeister, B. B., Blum, L. H., \& Lorge, I (Eds). - Escala de Maturidade Mental Colúmbia - 3" Edição. São Paulo: Casa do Psicólogo.

Anastácio-Pessan, F. L., Almeida-Verdu, A. C. M., Bevilacqua, M. C., \& de Souza, D. G. (2015). Usando o Paradigma de Equivalência para Aumentar a Correspondência na Fala de Crianças com Implante Coclear na Nomeação de Figuras e na Leitura. Psicologia: Reflexão e Crítica, 28(2), 365-377. doi: 10.1590/1678-7153.201528217

Assis, G. J. A., \& Santos, M. B. (2010). PROLER (versão 6.4) - Sistema Computadorizado para o Ensino de Comportamentos conceituais. Belém, PA: Universidade Federal do Pará.

Bandini, C. S. M., Sella, A. C., Postalli, L. M. M., Bandini, H. H. M., \& Silva, E. T. P. (2012). Efeitos de tarefas de seleção sobre a emergência de nomeação em crianças. Psicologia: Reflexão Crítica, 25(3), 568-577. doi:10.1590/S0102-79722012000300017

Battaglini, M. P., Almeida-Verdu, A. C. M., \& Bevilacqua, M. C. (2013). Aprendizagem via exclusão e formação de classes em crianças com deficiência auditiva e implante coclear. Acta Comportamentalia, 21(2), 20-35.

Byiers, B. J., Reichle J., \& Symons F. J. (2012). Singlesubject experimental design for evidence-based practice. American Journal of Speech-Language Pathology, 21, 397-414. doi: 10.1044/10580360(2012/11-0036)

Camarata, S. (1993). The application of naturalistic conversation training to speech production in children with speech disabilities. Journal of Applied Behavior Analysis, 26(2), 173-182. doi: 10.1901/jaba.1993.26173.

Castiquini, E. A. T., \& Bevilacqua, M. C. (2000). Escala de integração auditiva significativa: procedimento adaptado para a avaliação da percepção da fala. Revista da Sociedade Brasileira de Fonoaudiologia, 4(6), 5160.

da Silva, W. R., de Souza, D. G., de Rose, J. C., Lopes Jr., J., Bevilacqua, M. C., \& McIlvane, W. J. (2006). Relational learning in deaf children with cochlear implants. Experimental Analysis of Human Behavior Bulletin, 24, 1-8.

de Rose, J. C. (2005). Análise comportamental da aprendizagem de leitura e escrita. Revista Brasileira de Análise do Comportamento, 1,29-50. doi: 10.18542/rebac.v1i1.676

de Rose, J. C., de Souza, D. G., \& Hanna, E. S. (1996). Teaching reading and spelling: exclusion and stimulus equivalence. Journal of Applied Behavior Analysis, 29(4), 451-469. doi: doi.org/10.1901/jaba.1996.29-451 de Souza, D. G., Hanna, E. S., de Rose, J. C., Fonseca, M. L., Pereira, A. B, \& Sallorenzo, L. H. (1997). Transferência de controle de estímulos de figuras para texto no desenvolvimento de leitura generalizada. Temas em Psicologia, 5, 33-46.

Dube, W. V., McDonald, S. J., McIlvane, W. J., \& Mackay, H. A. (1991). Constructed-response matching to sample and spelling instruction. Journal of Applied Behavior Analysis, 24(2), 305-317. doi: 10.1901/jaba.1991.24-305

Dunn, L. M., \& Dunn, D. M. (2007). Peabody Picture Vocabulary Test, Fourth Edition. Bloomington, MN: Pearson.

Erber, N. P. (1982). Auditory training. Washington DC: A. G. Bell Association of Deaf.

Fagan, M. K., \& Pisoni, D. B. (2010). Hearing Experience and Receptive Vocabulary Development in Deaf Children With Cochlear Implants. The Journal of Deaf Studies and Deaf Education, 15(2), 149-161. doi: 10.1093/deafed/enq001

Ferrari, C., de Rose, J. C., \& Mcllvane, W. J. (1993). Exclusion vs. selection training of auditory-visual conditional relations. Journal of Experimental Child Psychology, 56, 49-63. PMID: 8366325.

Fienup, D. M., \& Critchfield, T. S. (2011). Transportability of equivalence-based programmed instruction: efficacy and efficiency in a college classroom. Journal of Applied Behavior Analysis, 44(3), 435-50. doi: 10.1901/jaba.2011.44-435

Frampton, S. E., Wymer, S. C., Hansen, B., \& Shillingsburg, M. A. (2016). The use of matrix training to promote generative language with children with autism. Journal of Applied Behavior Analysis, 49(4), 869-883. doi: 10.1002/jaba.340

Gast D. L., \& Ledford J. R. (2014). Single case research methodology: Applications in special education and behavioral sciences. 2nd ed. New York, NY: Routledge.

Geers, A. E. (1994). Techniques for assessing auditory speech perception and lipreading enhancement in young deaf children. Volta Review, 96(5), 85-96.

Goldstein, H. (1983). Training generative repertoires within agent-action-object miniature linguistic systems with children. Journal of Speech and Hearing Research, 26(1), 76-89. doi: 10.1044/jshr.2601.76

Golfeto, R. M. (2010). Compreensão e produção de fala em crianças com surdez pré-lingual usuárias de implante coclear (Tese de doutorado). Universidade Federal de São Carlos, São Carlos.

Golfeto, R. M., \& de Souza, D. G. (2015). Sentence production after listener and echoic training by prelingual deaf children with cochlear implants. Journal of Applied Behavior Analysis, 48(2), 363-375. doi: 10.1002/jaba.197

Greer, R. D., \& Ross, D. E. (2008). Verbal behavior analysis: Inducing and expanding new verbal capabilities in children with language delays. Boston: Allyn \& Bacon.

Guess, D. (1969). A functional analysis of individual differences in generalization between receptive and 
productive language in retarded children. Journal of Applied Behavior Analysis, 2(1), 55-64. doi: 10.1901/jaba.1969.2-55.

Hanna, E. S., de Souza, D. G., de Rose, J. C., \& Fonseca, M. L. (2004). Effects of delayed constructed-response identity matching on spelling of dictated words. Journal of Applied Behavior Analysis, 37(2), 223-227. doi: 10.1901/jaba.2004.37-223

Kazdin, A. E. (1982). Single case research designs: methods for clinical and applied settings. New York: Oxford.

Lamarre, J., \& Holland J. G. (1985). The functional independence of mands and tacts. Journal of the Experimental Analysis of Behavior, 43(1), 5-19. doi: 10.1901/jeab.1985.43-5

Levine, D., Stother-Garcia, K., Golinkhoff, R., \& HirshPasek, K. (2016). Language development in the first year of life: what deaf children might be missing before cochlear implantation. Otology \& Neurotology, 37(2), 10.1097/MAO.000000000000090.

Lucchesi, F. M., Almeida-Verdu, A. C. M., Buffa, M. J. M. B., \& Bevilacqua, M. C. (2015). Efeitos de um Programa de Ensino de Leitura sobre a Inteligibilidade da Fala de Crianças Usuárias de Implante Coclear. Psicologia: Reflexão e Crítica, 28(3), 500510. doi: 10.1590/1678-7153.201528309

Lucchesi, F. D. M., Almeida-Verdu, A. C. M., \& de Souza, D. G. (2018). Reading and speech intelligibility of a child with auditory impairment and cochlear implant. Psychology \& Neuroscience, 11(3), 306-316. doi: $10.1037 /$ pne0000139

Lund, E., \& Douglas, M. (2016). Teaching vocabulary to preschool children with hearing loss. Exceptional Children, 83, 26-41. doi: 10.1177/0014402916651848

Mackay, H. A. (2013). Developing syntactic repertoires: Syntheses of stimulus classes, sequences, and contextual control. European Journal of Behavior Analysis, $\quad$ 14(1), 69-85. doi: 10.1080/15021149.2013.11434446

Mackay, H. A., \& Sidman, M. (1984). Teaching new behavior via equivalence relations. In P. H. Brooks, R. Sperber, \& C. MacCauley (Eds.), Learning and cognition in the mentally retarded, (pp. 493-513). Hillsdale: Erlbaum.

Matos, M. A., Avanzi, A. L., \& McIlvane, W. J. (2006). Rudimentary reading repertoires via stimulus equivalence and recombination of minimal verbal units. The Analysis of Verbal Behavior, 22(1), 3-19. PMID: 22477340

Moret, A. L. M., Bevilacqua, M. C., \& Costa, O. A. (2007). Implante Coclear: Audição e Linguagem em crianças deficientes auditivas pré-linguais. Pró-Fono, 19(3), 295-304. doi: 10.1590/S010456872007000300008

Munafò, M. R., Nosek, B. A., Bishop, D. V. M., Button, K. S., Chambers, C. D., du Sert, N. P., Simonsohn, U., Wagenmakers, E., Ware, J. J., \& Ioannidis, J. P. A. (2017). A manifesto for reproducible science. Nature
Human Behaviour, 1, 1-9. doi: 10.1038/s41562-0160021

Neves, A. J., Almeida-Verdu, A. C. M., Assis, G. J. A., Silva, L. T. N., \& Moret, A. L. M. (2018), Improving oral sentence production in children with cochlear implants: effects of equivalence-based instruction and matrix training. Psicologia: Reflexão e Crítica, 31(14). doi: 10.1186/s41155-018-0095-y

Peterson, N. R., Pisoni, D. B., \& Miyamoto, R. T. (2010). Cochlear implants and spoken language processing abilities: review and assessment of the literature. Restorative neurology and neuroscience, 28(2), 237-50. doi: 10.3233/RNN-20100535

Rique, L. D., Almeida-Verdu, A. C. M., Silva, L. T. N., Buffa, M. J. M. B., \& Moret, A. L. M. (2017). Leitura após formação de classes de equivalência em crianças com implante coclear: precisão e fluência em palavras e textos. Acta Comportamentalia, 25(3), 307-327.

Robbins, A., \& Osberger, M. J. (1991). Meaningful use of speech scale (MUSS). Indianapolis: Indiana Univeristy School of Medicine.

Ruff, S., Bocklet, T., Nöth E, Müller, J., Hoster, E., \& Schuster, M. (2017). Speech Production Quality of Cochlear Implant Users with Respect to Duration and Onset of Hearing Loss. ORL, 79(5), 282-294. doi: $10.1159 / 000479819$

Share, D. L. (1999). Phonological recoding and orthographic learning: A direct test of the self-teaching hypothesis. Journal of Experimental Child Psychology, 72(2), 95-129. doi:10.1006/jecp.1998.2481

Sidman, M. (1986). Functional analysis of emergent verbal classes. In T. Thompson \& M. D. Zeiler (Orgs.), Analysis and integration of behavioral units (pp. 213245). Hillsdale: Lawrence.

Sidman, M. (2000). Equivalence relations and the reinforcement contingency. Journal of the Experimental Analysis of Behavior, 74(1), 127-146. doi: 10.1901/jeab.2000.74-127.

Sidman, M. (1960). Tactics of scientific research: Evaluating experimental data in psychology. Boston: Authors Cooperative.

Sidman, M., \& Tailby, W. (1982). Conditional discriminations vs. matching-to-sample: an expansion of the testing paradigm. Journal of the Experimental Analysis of Behavior, 37(1), 5-22. doi: 10.1901/jeab.1982.37-5

Silva, R. V., Neves, A. J., \& Almeida-Verdu, A. C. M. (2017). Ensino de relações de equivalência com sentenças de cinco termos e produção oral em uma criança com implante coclear. Acta Comportamentalia, 25(3), 289-306.

Skinner, B. F. (1957). Verbal Behavior. New York: Appleton - Century - Crofts.

Spencer, L. J., \& Oleson, J. J. (2008). Early Listening and Speaking Skills Predict Later Reading Proficiency in Pediatric Cochlear Implant Users. Ear and Hearing, 29(2), 270-280. doi: 10.1097/01.aud.0000305158.84403.f7 
Svirsky, M. (2017). Cochlear implant and electronic hearing. Physics Today, 70(2), 52-58. doi: 10.1063/PT.3.3661

Svirsky, M. A., Robbins, A. M., Kirk, K. I., Pisoni, D. B., \& Miyamoto, R. T. (2000). Language development in profoundly deaf children with cochlear implants. Psychological Science, 11(2), 153-158. doi: 10.1111/1467-9280.00231.
Yamamoto, J., \& Miya, T. (1999). Acquisition and transfer of sentence construction in autistic students: Analysis by computer-based teaching. Research in Developmental Disabilities, 20(5), 355-377. doi: 10.1016/S0891-4222(99)00017-7

Submetido em: 21/08/2018 Aceito em: 17/06/2019 